\title{
De Leibniz às máquinas sociais: uma visão histórica do surgimento dos agentes inteligentes de informação sob a ótica da ciência da informação
}

Celio Andrade Santana

http://orcid.org/0000-0003-0398-3172

Camila Oliveira Lima ${ }^{I I}$

http://orcid.org/0000-0002-4526-6166

Amanda Almeida Nunes ${ }^{I I I}$

http://orcid.org/0000-0003-0860-1997

${ }^{I}$ Universidade Federal de Pernambuco, PE, Brasil. Doutorem Ciências da Computação.

${ }^{I I}$ Universidade Federal de Pernambuco, PE, Brasil. Doutoranda no PPGCI-UFPE.

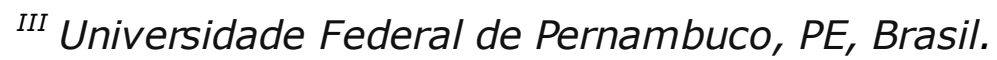
Mestre em Ciência da Informação

http://dx.doi.org/10.1590/1981-5344/3554

Tem como objetivo investigar o contexto histórico do desenvolvimento das ideias que culminaram com o surgimento dos agentes de mineração. Pressupõe, hoje, que cerca de metade da informação processada na Internet é feita por agentes o que estimula uma discussão sobre o papel dos bots na contemporaneidade, bem como da relação destes com pessoas e seus dados. A justificativa deste trabalho se dá pela observação do cenário atual em que tais agentes já interagem com as 
pessoas e pelo distanciamento presumido, do objeto de estudo que resulta na escassez de publicações a partir da CI. Apresenta como as necessidades informacionais que impulsionaram o surgimento da Ciência da Informação também inspiraram a criação dos agentes de mineração. O Procedimento metodológico utilizado foi uma revisão bibliográfica que parte do desejo de Leibniz em criar o Calculus Ratiocinator e segue até a contemporânea teoria das Máquinas Sociais. Sugere como conclusão, por um lado, que a CI já desenvolveu o seu olhar sobre a evolução dos Agentes de Mineração, que a princípio era atribuída, apenas, à lógica e matemática, e por outro lado articular estas desconexas e esparsas visões dos contextos próprios dos agentes de mineração.

Palavras-chave: Agentes de Mineração. Máquinas Sociais. Internet 3.0.

\section{From Leibniz to machines social: a historical overview of the emergence of intelligent agents of information from the perspective of information science.}

Aims to investigate the historical context of the development of ideas that culminated in emergence of mining agents. Half of the information processing on the Internet is made by agents stimulating the discussion about the role of bots in the contemporary world, as well as their relationship with people and their data. The justification of this work is the observation of the current scenario in which such agents already interact with the people and by the presumed distancing of the object of study that results in the scarcity of publications from the IS. It presents how the informational needs that drove the emergence of Information Science also inspired the 
creation of mining agents. The methodological procedure used was a bibliographical revision that starts from the desire of Leibniz in creating the Calculus Ratiocinator and follows until the contemporary theory of the Social Machines. It suggests as a conclusion, on the one hand, that IS has already developed its view on the evolution of Mining Agents, which was initially attributed only to logic and mathematics, and on the other hand to articulate these disjointed and disparate visions of their own contexts of mining agents.

Keywords: Mining Agents. Social Machines. Internet 3.0.

Recebido em 02.06.2018 Aceito em 22.03.2021

\section{Introdução}

No final do último milênio Manuel Castells (1999) afirmou que a humanidade vivia um momento histórico em que a base de todas as relações era estabelecida através da informação, sua capacidade de processamento e da geração de conhecimento. A reflexão de Castells sobre a revolução ocorrida com a difusão da Internet culmina com a constatação de que fronteiras de informação haviam sido derrubadas. A genialidade de Castells foi compreender, naquele momento, que a, até então, rede mundial de computadores se tornaria, inexoravelmente, uma rede de pessoas. Passadas quase duas décadas, é possível afirmar que a previsão de Castells fora acertada e a Internet se coloca como um espaço onde pessoas coexistem, interagem e colaboram em um ambiente de complexidade social, cultural, política, econômica e tecnológica.

Castells não foi o único a compreender que a Internet não se limitaria a uma rede de computadores. Outras visões para a rede emergiram, por exemplo, a ideia de Aharony, Reed e Lippman (2009) que envolve big data e dados ligados (linked data) sugeria um outro tipo de rede, não de computadores e nem de pessoas, mas sim, de dados interligados como uma teia. Outra rede que tem recebido certo destaque é a Internet das Coisas idealizada por Rafi Haladjian (2005 apud KOPETZ, 2011) que trata da conexão de dispositivos eletrônicos em/na rede que compartilham um mesmo espaço virtual e que agem, do ponto de vista sistêmico, como uma única entidade. 
Essa diversidade de atores conectáveis em rede foi vislumbrada por Luciano Floridi (2002) ao apresentar, em sua Filosofia da Informação, o conceito de infosfera que consiste em um ecossistema informacional constituído por entidades informacionais chamadas Inforgs, não necessariamente humanas, que tem como principal função colaborar com a dinâmica da informação na infosfera.

Recuero (2011) aponta que há uma ênfase em pesquisas ligadas à relações humanas em redes sociais virtuais e nas novas formas de interação que surgiram nestes ambientes. Entretanto, quando se trata da investigação do papel de outros atores atuantes na Internet, não são encontradas pesquisas voltadas aos bots. O primeiro trabalho publicado em um veículo nacional da área da Ciência da Informação que trata de sujeitos informacionais não humanos foi publicado por Biolchini (2003). Nele o autor sugere o desenvolvimento de agentes inteligentes de informação (AII) para a área médica. Vickery e Vickery (2004) sugerem a seguinte definição para os AII:

É um agente inteligente (racional), atuando em um ambiente imprevisível, apresentando um comportamento autônomo e flexível sendo capaz de: (i) acessar uma ou várias fontes de dados, informações e conhecimento, (ii) adquirir, fornecer e manter informações relevantes, e (iii) se comunicar com pessoas e outros agentes. (VICKERY; VICKERY, 2004, p. 318. Tradução Nossa)

A comunicação entre AIIs vem sendo alvo de questionamentos por uma parte da indústria e da academia, uma vez que as informações utilizadas por eles pertencem à pessoas que, por vezes, sequer imaginam que seus dados são utilizados por máquinas. Luciano Floridi (2014) destaca a importância de se observar a dinâmica da comunicação entre AIIs por uma questão quantitativa, apresentada na Figura 1, onde se estima que, em 2020, existirão 50 bilhões dispositivos conectados em rede para "apenas" 8 bilhões de pessoas. 
Figura 1 - O crescimento da população mundial e de dispositivos conectados.

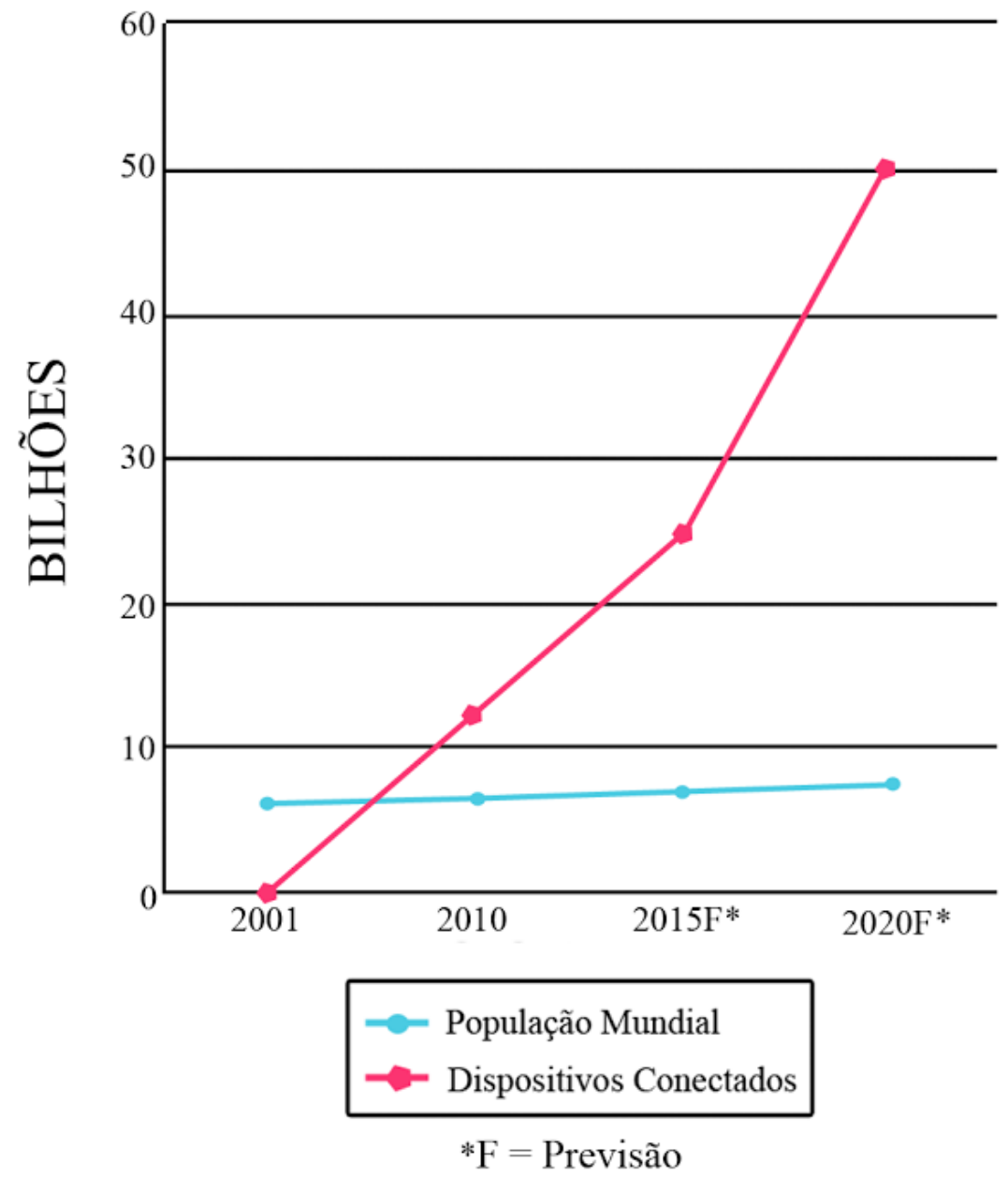

Fonte: Floridi (2014)

A questão levantada por Floridi é: "Diante destes números, será que toda a comunicação na Internet terá que necessariamente envolver seres humanos?". A Imperva-Incapsula respondeu esta questão para o ano de $2015^{1}$ e concluiu que, naquele ano, 48,5\% do tráfego da Internet se deu a partir de AIIs. O mesmo Floridi (TSVETKOVA et al., 2016) afirmou que a ciência ainda conhece muito pouco sobre como as MPIs interagem na Internet. Para chegar a tal questionamento, os pesquisadores investigaram no Wikipediaz a quantidade de vezes em que os seres humanos revertiam as alterações feitas por outros seres humanos, bem como a quantidade de vezes que Robôs (bots) revertiam as alterações feitas por outros robôs. Em um período de 10 anos, os humanos revisores desfizeram, em média, 3 alterações feitas por outros seres humanos, enquanto que os bots desfizeram, em média, 150 alterações feitas por 
outros bots. A conclusão dos autores é que estes AIIs avaliam informações uns dos outros por anos.

Pesquisadores da Ciência da Informação já reconhecem que entidades não humanas estão em constante atuação na rede. Jorente, Santos e Vidotti (2009) afirmam que, o homem tem deixado de ser o único protagonista ativo no processo de apreensão e uso dos dados e na consequente transformação em conhecimento, uma vez que AIIs podem exercer funções autônomas e parcialmente ativas. Duque e Carvalhedo (2008) sugerem que AIIs atuam na Internet de maneira imperceptível em auxílio aos usuários, conversando e compreendendo informações que circulam pela web. Bernes Lee (2001) afirma que a web 1.0 foi desenvolvida para ser processada para leitura dos seres humanos, enquanto que a web 3.0, seria processada tanto por seres humanos quanto por máquinas chamadas por ele de softbots, que seriam capazes de compreender a informação e seus significados.

Desta forma, o objetivo geral desta pesquisa é apresentar um panorama histórico, sob a ótica de publicações em veículos voltados a Ciência da informação, das ideias que contribuíram para o surgimento dos AIIs e mostrar que uma gama de conceitos, aparentemente de cunho exclusivamente tecnológico, também contribuiu com algum aspecto da CI. A partir deste olhar é possível observar que o desenvolvimento dos conceitos que possibilitam a existência de tais máquinas não surgiu, por outra razão, a não ser solucionar problemas relativos à informação.

A argumentação exposta neste artigo foi pautada numa extensa revisão bibliográfica, utilizando, em sua maioria, daquelas publicadas em veículos dedicados à Ciência da Informação. O critério para a seleção desta literatura foi a presença do debate da relação 'homem-tecnologiainformação'. Contudo, um maior interesse foi dado às pesquisas que analisavam como o desenvolvimento de tecnologias, não necessariamente ligadas a computadores, afetou a forma pela qual as pessoas lidam com informações. Para iniciar essa reflexão sobre AIIs, devemos voltar até o século XVII e analisar uma parte da visão de Gottfried W. Leibniz e a sua visão sobre como as bibliotecas poderiam se modernizar para resolver problemas relativos a informação.

\section{0 sonho de Leibniz}

Gottfried Wilhelm Leibniz (1646 - 1716), alemão, foi filósofo, doutor em direito, matemático e bibliotecário que, embora não tenha tido grande proeminência na área da biblioteconomia, se propôs a resolver alguns problemas relativos às bibliotecas de sua época. A visão de Leibniz como pioneiro das Ciências da Informação é trazida por Pieruccini (2013, p. 12): 
Leibniz julga ter como tarefa principal colocar a biblioteca em consonância com as atualidades científicas e literárias de seu tempo e organizar a coleção para facilitar seu uso. Por esta razão, ele pode ser considerado como um pioneiro das ciências da informação. PIERUCCINI (2013, p. 12)

Matheus (2005) sugere que Leibniz foi o criador de um de sistema de indexação de resumos classificados em linguagem universal onde se preconizava o trabalho colaborativo entre sociedades científicas. Pombo (2010) afirma que Leibniz percebia a necessidade de organizar informação e, já naquela época, previa que a desordem dos acervos seria quase intransponível. Em pouco tempo a quantidade de autores cresceria de modo exponencial e que estes seriam expostos ao esquecimento total devido ao excesso de informações desordenadas.

Anjos (2008) sugere que as ideias de Leibniz foram fundamentais para alguns autores consagrados. Segundo ele, a obra Traité de documentation de Paul Otlet (1934) baseou-se nas ideias de Leibniz para defender uma Classificação Decimal Universal (CDU) como linguagem universal da ciência com uma notação numérica permitindo que, posteriormente, fosse possível compilar o Repertório Bibliográfico Universal (RBU). Outra possível influência de Leibniz se deu sobre Melvil Dewey quando este criou a Classificação Decimal de Dewey (CDD) também a partir de uma notação numérica. Dahlberg (1979) afirma que Leibniz também pode ter influenciado Shiyali Ranganathan para a criação da fórmula das facetas que era um tipo de matemática qualitativa que Leibniz tentou ao analisar os assuntos.

Ressalta-se que estas contribuições de Leibniz sobre sistemas de classificação e indexação provieram do desejo em criar um método onde informação pudesse ser processada de uma forma "mecânica". Para isso, ele idealizou uma linguagem científica universal complementada por um sistema dedutivo simbólico, que poderia substituir a argumentação discursiva pelo cálculo em todos os campos do saber e que fosse capaz de processar e unificar todo o conhecimento existente (ANJOS 2008). Gleick (2013) afirma que Leibniz tinha como objetivo criar uma linguagem universal, chamada Characteristica Universalis, compreendida como uma base matemática que permitiria descrever todo o conhecimento existente.

Foram encontradas evidências de que as descobertas de Leibniz foram objetos de estudo de pesquisadores da CI, mas, o que, provavelmente, distanciou Leibniz deste campo do saber não foi a elaboração de uma teoria da linguagem universal em si, mas sim, a forma como se deu a criação desta linguagem. Peckhaus (2004) aponta que o intuito de Leibniz era tornar qualquer conhecimento compreensível, e isso direcionou os seus esforços, não mais para a criação, mas sim como 
processar, de forma mecânica, os símbolos da Characteristica Universalis e como decodificar mensagens escritas nesta linguagem. Leibniz idealizou um método de cálculo simbólico, conhecido como Calculus Ratiotinator, que tinha como intuito processar os símbolos representados pela Characteristica Universalis e essa nova forma de raciocínio foi o embrião daquilo viria ser conhecido como Lógica.

Retornando ao campo da CI, Gleick (2013, p. 185) faz a relação desta lógica criada por Leibniz e o modo como seres humanos processam informação (raciocínio):

A invenção da escrita, catalisou a lógica, tornando possível raciocinar a respeito do raciocínio - trazer diante dos olhos um encadeamento de ideias para um exame atento - e então, tantos séculos mais tarde, a lógica era reanimada com a invenção de máquinas capazes de trabalhar a partir de símbolos. GLEICK (2013, p. 185)

Leibniz, ainda que de forma primitiva, tentou solucionar a questão sobre como informação poderia ser processada, de forma mecânica, a partir da lógica e da matemática. Essa maneira "pouco ortodoxa" encontrada por ele para resolver os problemas de suas bibliotecas, pode ter influenciado alguns precursores da CI que seguiram seus próprios meios de desenvolver a biblioteconomia e a CI. Leibniz seguiu um caminho, chamado mais de um século depois de lógica, que não é tão comum na $\mathrm{CI}$, mas, que decerto modificou a relação do homem com a informação.

\section{A lógica e a codificação do pensamento}

Foi mostrado como a lógica de Leibniz pode ter influenciado alguns dos nomes que contribuíram para o desenvolvimento das bibliotecas e da CI, mas, se quisermos prover uma visão da lógica nesta área, temos que retomar as origens da lógica da Grécia antiga. Gleick (2013) afirma que Aristóteles se mostrou capaz de desvendar problemas que envolviam premissas e conclusões sem exigir, nem pressupor, nenhuma experiência pessoal prévia com certas questões, mas, ainda assim, era possível raciocinar sobre elas. Aristóteles propunha que, mesmo sem possuir tal domínio, era possível criar conhecimento por meio da manipulação de palavras e talvez até criar uma forma superior de conhecimento, chamada pelos gregos de Lógica. Crnkovic (2003) aponta que Leibniz encontrou uma falha na lógica aristotélica ao perceber que a linguagem natural, apesar de seus poderosos recursos de comunicação, muitas vezes torna o 
raciocínio obscuro como um sistema imperfeito de pensamentos tornando difícil utilizar a razão a partir desta linguagem.

Leibniz afirma que "todas as ideias humanas podem ser expressas a partir de conceitos primitivos". Podendo, então, atribuir símbolos para esses conceitos primitivos para que seja possível formar conceitos derivados por meios de combinações de símbolos (CRNKOVIC, 2003, p. 3). A lógica aristotélica não seguia nenhum método formal enquanto que Leibniz idealizou um modo, chamado hoje de lógica simbólica, ainda que imperfeito para processar qualquer tipo de conhecimento. Entretanto, demorou 150 anos para que fosse proposta a primeira máquina para a realização de cálculos complexos. Charles Babbage idealizou a Máquina Diferencial que utilizava como base a numeração decimal para realização de cálculos complexos. Babbage propunha mecanizar processos matemáticos a partir de premissas o que tornaria esta máquina diferencial o primeiro processador de informação, ainda que apenas numérica, programável (KURZWEIL; RICHTER; SCHNEIDER, 1990).

Retornando à CI, Gleick (2013, p.164) relaciona a Máquina Diferencial ao conceito de informação ao afirmar que ela foi projetada para produzir vastas quantidades de uma determinada commodity (números).

A máquina abrira um canal do mundo corpóreo da matéria para um mundo de pura abstração, a máquina não consumia nenhuma matéria-prima, não havia peso no que entrava nem no que era produzido, mas, precisava de uma força considerável para ativar suas engrenagens. O conjunto completo desses mecanismos seria suficiente para preencher uma sala, pesando várias toneladas. A produção de números, conforme concebida por Babbage, exigia um grau de complexidade mecânica que estava no limite da tecnologia disponível. (GLEICK, 2013, p.164)

Babbage também tentou construir uma linguagem universal que fosse livre das idiossincrasias e imperfeições da linguagem natural. Trabalhando de maneira sistemática ele conseguiu criar uma gramática e passou a registrá-la por escrito, mas, viu-se impossibilitado de prosseguir seus estudos ao se deparar com problemas de armazenamento de dados (AABOE, 1964).

Um pouco mais tarde, George Boole publicou a obra Laws of Thought (1864) que mistura teorias matemáticas, lógica e probabilidades que aproximava a lógica da álgebra, ao incorpora-la à matemática, ressaltando a analogia entre os símbolos algébricos e os lógicos. Boole criou a álgebra da lógica, chamada também de álgebra booleana, e que 
mais tarde viria ser aplicada na construção dos computadores (MUHERONI apud SILVA; PALETTA, 2016).

Gleick (2013) sugere que Boole enxergava seu sistema como uma matemática sem números. Ele acreditava que as leis definitivas da lógica se tornariam matemáticas em sua forma e expressão apesar de não pertencer à matemática das quantidades (aritmética). Até àquele momento, a lógica pertencera ao domínio da filosofia e Boole o estava direcionando à matemática e ao fazê-lo, projetou uma nova forma de codificação.

Neil (1865, p. 29) reproduziu as exatas palavras de Boole em relação a lógica por ele criada:

A linguagem é um instrumento da razão humana e não apenas um meio para a expressão do pensamento. Os elementos a partir dos quais toda a linguagem se constitui são os signos e os símbolos. As palavras são signos e às vezes dizemos que elas representam coisas; outras vezes, as operações por meio das quais a mente reúne as simples ideias de coisas e as transforma em concepções complexas (NEIL, 1869, p.29, tradução nossa).

O destaque dado a Babbage e a Boole nesta sessão é simbólico uma vez que, o caminho trilhado por ambos, representa o início do desenvolvimento das duas vertentes necessárias para a concretização do sonho de Leibniz: (i) a máquina (Hardware) capaz de mecanizar o processamento da informação (Babbage) e (ii) a formalização da lógica (Software) que representaria o "modo de raciocínio" utilizado por esta máquina (Boole). O desenvolvimento destas duas vertentes ainda é pouco mencionado na $\mathrm{CI}$, mas, os dois séculos de desenvolvimento destas duas vertentes tornaram possível as descobertas de três cientistas: John Von Neumman, Claude Shannon e Norbert Wiener, sendo estes dois últimos mais conhecidos dentro da CI.

\section{Os bits de Shannon, a cibernética de Wiener e o computador de Von Neumann.}

Vannevar Bush, em sua obra As we may think (1945), sugere que problemas relativos à informação "é uma questão que deveria ser solucionada por máquinas". Ao se mencionar Bush na CI, costumeiramente, existe uma referência ao Memex, um apetrecho tecnológico que armazena e recupera documentos mediante associação de palavras e que nunca chegou a ser construído. O que pouco se sabe é que Bush, de fato, estava criando uma máquina chamada analisador diferencial e que recrutou Claude Shannon que mais tarde escreveria, 
junto com Weaver (1949), a teoria matemática da comunicação (GLEICK, 2013). Esta teoria ganhou importância pela possibilidade de quantificar a informação que poderia transitar por um canal de comunicação. Este cálculo se dava a partir da análise estatística das letras contidas nas palavras de um idioma. (GUEDES; ARAÚJO JÚNIOR, 2014).

O que se observa nos estudos da CI relativos à Shannon é a menção ao sistema geral de comunicação proposto por ele e que contém cinco elementos: (i) fonte de informação, (ii) transmissor, (iii) canal de comunicação, (iv) receptor e (v) destinatário. O que praticamente se desconhece é a importância de Shannon para o surgimento dos computadores. Por orientação de Bush, Shannon criou o primeiro elo entre a lógica mecânica analógica com a lógica binária de Boole e esta não é uma conexão trivial de se realizar uma vez que, os mundos da eletricidade e da lógica pareciam distantes entre si. O analisador diferencial era composto por dispositivos comuns como engrenagens e polias e dispositivos eletromecânicos (relés) sendo este o primeiro dispositivo mecânico a simular dígitos binários. E foi esta a motivação que fez Shannon aprender a álgebra de Boole já que ela também descreveria circuitos eletrônicos (GLEICK, 2013).

Assim como Boole, Shannon necessitava de apenas dois elementos para suas equações: zeros e uns, criando assim o binary digit (bit) que surgia como uma unidade quantificadora de informação. A partir disso, questões sobre a quantidade de informação transportada de um ponto a outro poderiam ser facilmente respondidas e o bit poderia se tornar uma unidade padrão para mensurar qualquer tipo de informação. Então, mais do que criar uma unidade de quantificação, Shannon possibilitou que qualquer informação fosse reduzida a um certo número de bits e consequentemente, posta sob a mesma base binária (GLEICK, 2013).

Gleick (2013) afirma que Shannon pode ter sofrido influência do professor Norbert Wiener, que propunha a criação de uma nova teoria chamada Cibernética (1948). A Cibernética representa um movimento filosófico que sintetiza o estudo da comunicação e controle e como o ser humano e as máquinas participam deste processo. Wiener em conjunto com Rosenblueth e Bigelow (1943) sugeriu que a cibernética correspondia a uma nova interpretação do homem sobre o universo e sociedade. Essa reflexão passa pela afirmação de que a inteligência pode se aplicar também às máquinas afinal, se um comportamento para atingir um determinado fim é objetivo, este pode ser imputado a uma máquina ao invés de um humano. Com esse pensamento, Wiener e a Cibernética começaram a ser associados a um tipo de máquina que estava habitando a consciência das pessoas naquele momento: os computadores.

Essa associação só pôde se tornar realidade graças à Neumann János ou, como ficou conhecido mais tarde, John Von Neumann (HEIMS, 
1980). Gleick (2013) afirma que Von Neumann foi o primeiro a compreender que a lógica não seria capaz de provar todas as verdades sobre as relações dos números naturais (aritmética) e que, portanto, nem tudo poderia ser computado. Von Neumann também assumiu a vanguarda na criação de uma arquitetura para computadores eletrônicos ao reconhecer o fato de que processos digitais ocorrem em um mundo mais confuso, semelhante a um neurônio que salta entre dois estados diferentes. A arquitetura por ele proposta, conhecida como arquitetura de Von Neumman, é utilizada até hoje pelos computadores contemporâneos e é composta por três partes: (i) um "armazém de informações" que correspondente à memória do computador, (ii) uma "unidade executiva", que se encarrega das operações individuais; e (iii) um "controle", que administra uma lista de instruções para execução (GLEICK, 2013).

Van Neumman finalmente usou esta arquitetura para construir um computador chamado EDVAC (Electronic Discrete Variable Automatic Computer) que utilizava lógica binária e dava início a concretização do sonho de Leibniz. Começava a ficar muito claro que o computador era mais complexo do que outras máquinas contemporâneas pelo fato da utilização de uma lógica de propósito geral que o tornava programável. Embora o EDVAC não tenha sido a primeira máquina programável, este título que compete ao tear de Joseph-Marie Jacquard, este foi o primeiro a utilizar uma sequência de instruções digitais, conhecidas hoje como software, e criadas por outro gênio da matemática, Alan Mathinson Turing.

\section{Alan Turing e as máquinas inteligentes}

Em 1936 o matemático britânico Alan Turing (1912-1954), considerado precursor da Ciência da Computação e da Inteligência Artificial, anteviu que seria possível executar operações lógicas por meio de uma máquina que respeitasse regras de um sistema matemático formal. Turing vislumbrou a possibilidade de que máquinas poderiam se tornar inteligentes a partir da criação de um modelo matemático teórico para um computador universal que fosse programável (PECKHAUS, 2004).

Turing idealizou um modelo, chamado Máquina Universal (MU), que sugeria a existência de uma máquina capaz de simular o comportamento de qualquer outra máquina capaz de realizar cálculos. Segundo Peckhaus (2004) esta era "uma máquina que contem infinitas máquinas, pensadas a partir de um sistema processador de símbolos e da lógica". Para Turing, a realização de qualquer cálculo, deveria se basear em uma sequência de passos onde um conjunto de símbolos deveria ser processado até que um dos estados finais fosse atingido (HERKEN, 1992, p.8). Essa idealização de Turing sugeriu, pelo menos, três elementos essenciais dos computadores: (i) a noção de algoritmo, já que todo o cálculo possui uma sequência de 
passos finita do estado inicial ao estado final; (ii) a noção de Software devido à possibilidade de se criar, de forma flexível, algoritmos para diversos propósitos e por fim (iii) a própria Computação que é o ato de realizar estas operações em cima dessa notação simbólica (HERKEN, 1992, p.8).

Turing se mostrou notável ao elaborar diversas teorias tais como o problema da parada (Entscheidungsproblem) e com a própria definição de programa (posteriormente chamada de software). Mas, o que trouxe reconhecimento a Turing foi a pergunta: "podem as máquinas pensar?" (TURING, 1950). O matemático sugeria um teste chamado jogo da imitação, conhecido como Teste de Turing, cujo objetivo era determinar se máquinas eram, ou não, capazes de "pensar". Turing afirmou que se uma máquina fosse concebida para jogar de maneira satisfatória a questão sobre máquinas pensantes não seria mais alvo de objeções e assim estas poderiam ser chamadas de inteligente (TURING, 1950).

O Teste de Turing foi concluído com sucesso pela primeira vez em $2014^{3}$, o que sugere alguma forma de inteligência. Turing foi o primeiro a formular o pensamento de que máquinas poderiam ser inteligentes 0 suficiente para participar de regimes de informação de forma autônoma. 0 que se observa atualmente é que a inteligência por trás dos computadores vem do tratamento de imensas massas de dados gerados pelas pessoas. $\mathrm{Na}$ época de Turing, ainda era pouco crível que pessoas gerassem tanta informação, e que a inteligência dos computadores viria exclusivamente da programação, e não de outras técnicas como aprendizado de máquinas. O que desviou o caminho das máquinas inteligentes dos algoritmos para a análise de dados se deu pela participação massiva de indivíduos comuns no processo de criação/geração de informação graças à realização de outro sonho, dessa vez de um jovem americano chamado Bill Gates, cujo desejo era que em "cada lar houvesse um computador".

\section{Os computadores se tornaram pessoais}

Ao Altair, de 1975, é atribuída a insígnia de primeiro computador pessoal (PC). Certamente foi o primeiro PC disponível ao público em geral, mas, em 1972, a Xerox Corporation decidiu investigar novas tecnologias, e como resultado, criou uma máquina chamada "Alta" desenvolvida para pertencer a um único indivíduo e ser usada em sua própria casa. O Alto era simplesmente uma tela vertical de televisão, acoplada a um teclado semelhante ao de uma máquina de escrever, e ambos eram conectados a uma caixa, um pouco maior que um nobreak atual, dentro da qual havia programas com instruções que a faziam funcionar (LAHAM, 2010).

Gehringer e London (2011) contam a história dos computadores pessoais e da relativa demora de quatro anos para que estes se tornassem de fato populares. A adoção dos PCs só se deu quando foram 
ultrapassados dois dos desafios: (i) Como tornar computadores amigáveis para leigos e (ii) como torná-los úteis para as pessoas? O primeiro desafio foi superado com o lançamento do computador Apple II que trazia um sistema operacional que simplificava seu uso. Já o segundo, só foi superado com o lançamento da planilha eletrônica Visicalc. Garcia e Souza (2013) corroboram essas dificuldades ao recapitular o pensamento de Licklider diretor da Advanced Research Projects Agency (ARPA), quando este passou a apoiar pesquisas para a interatividade humanocomputador por considerar o computador um parceiro inteligente que ainda necessitava aprimorar essa interatividade.

A IBM também criou a versão própria de $P C$ e a foi com ela que o jovem Bill Gates pôde realizar o seu sonho. Quando se trata da revolução dos PCs, chamamos a atenção para um aspecto citado por Solove (2004) quando este afirma que "o mais irreversível processo trazido pelos PCs foi a criação da vida virtual". Pessoas passaram a possuir documentos digitais que representavam, em parte, suas vidas e naquele momento ocorria uma migração em direção ao digital. Posteriormente, Levy (2010) chamou essa migração como de "novo nomadismo da humanidade" que passara a se apropriar dos espaços digitais.

Com o surgimento dos PCs, foi possível integrar as descobertas de todos os matemáticos aqui citados à vida do cidadão comum. A interação com os computadores se dava em dois sentidos: (i) do homem que aprende a usar o computador e (ii) do computador que tenta se adaptar ao seu usuário. Entretanto, o que se destaca com o surgimento dos PCs é a massificação da digitalização de informação que se encontrava ao alcance dos leigos, e seria óbvio pensar que em um mundo com bilhões de pessoas, uma imensa quantidade de informação digital seria gerada em pouco tempo. Mas outras revoluções se faziam necessárias para mudar a direção da interação homem-homem mediadas por computador para a interação máquina-máquina baseados nos dados criados por seres humanos.

\section{A internet 1.0 por Castells, Levy e Floridi}

Na década de 1990, o sonho de Gates já era realidade nos Estados Unidos onde cada lar já possuía, em média, um PC. Entretanto, neste momento, as atenções começaram a se voltar para outra "novidade" que propunha a construção de uma rede de computadores e foi chamada de Internet. Castells (2003) afirma que "o verdadeiro arranque da Internet global dá-se a partir da criação de protocolos convencionais que permitem o cruzamento de várias redes e uma comunicação muito mais abrangente e acessível". Esta mesma Internet fez com que o próprio Manuel Castells (1999) vislumbrasse uma sociedade conectada em um espaço 
democrático e livre, onde qualquer barreira poderia ser transposta a partir de poucos cliques.

Essa primeira versão da Internet, definida por Bernes Lee (1999) como Web 1.0, tinha como principal característica que a geração do conteúdo era realizada por poucos especialistas. Apesar desta Internet ainda ser caracterizada pelo grande número de consumidores de informação, esta foi, segundo Castells (2003), responsável por uma significativa transformação na economia, mercado, trabalho e gestão provocando mudanças de paradigmas na humanidade onde se promovia uma nova sociabilidade, em rede, baseada numa dimensão virtual que transcende o tempo e o espaço.

Pierre Levy (2010) também percebeu a revolução causada pela Internet ao sugerir a rede como um produto da "cibercultura" onde surgia um novo espaço de interações propiciado pela realidade virtual em que as pessoas experimentam novos tipos de relação. Floridi (1995) se questionou se ao se referir a Internet, nós estaríamos tratando do sistema digital internacional que agrega diversas redes de computadores ou, se estaríamos nos referindo a uma entidade fortuita que não poderia ser fisicamente percebida, que não possui significado de tempo e lugar e, que acima de tudo, potencializa as redes de interação que a constitui.

O que é se destaca na visão de Castells, Levy e Floridi é que, enquanto uma parcela considerável da academia ainda discutia a web como a rede mundial de computadores, estes vislumbraram a Internet como uma rede de pessoas capaz transformar aspectos sociais, culturais, econômicos e políticos por estabelecer um novo princípio de comunicação. E enquanto essa visão continuava a se espalhar, a evolução da Internet possibilitou uma maior participação das pessoas seguindo em uma direção cada vez mais próxima da Web Social chamada também de web 2.0.

\section{8 internet 2.0 - a rede se torna SMAC}

Em 2007, Maness apresentava um trabalho sumarizando como uma série de tecnologias recém-criadas na Internet seria capaz de alterar o funcionamento das bibliotecas tornando-as mais ágeis e eficientes, tornando-as mais colaborativas, de tempo real, multimídia e democrática. Essa evolução, agora possível, nas bibliotecas se deu a partir da evolução de própria Internet percebida por Tim O'Reilly e Dale Dougherty em 2004. Maness (2007) apresentou a visão particular da biblioteconomia sobre o assunto a partir a seguinte afirmação:

A melhor concepção de Biblioteca 2.0 neste momento seria uma interface de rede social que o usuário desenha. Isto é, um OPAC (Online Public Access Catalog) personalizado que incluem 
alimentadores RSS, blogs, wikis, tags, e perfis públicos e privados dentro da rede da biblioteca. Isto é a realidade virtual da biblioteca, um lugar onde alguém pode não apenas procurar por livros e revistas, mas interagir com uma comunidade e compartilhar conhecimento e entendimento (MANESS, 2007, p. 49).

A transformação para a biblioteca 2.0 sugerida por Maness não difere muito do que foi proposto em outras áreas de conhecimento. As pessoas passaram a compreender as ideias de Castells, Floridi e Levy de web social e das redes de pessoas que se apropriam de espaços virtuais. Toffler (2007) caracteriza estes novos usuários da rede como prosumers, ou seja, produtores e consumidores da informação colocando a Internet como a principal forma de comunicação entre pessoas.

Assim como aconteceu com a web 1.0, enquanto pessoas ainda observavam o caráter participativo e inclusivo da "nova" web 2.0 onde a sociedade transformava a rede, Wade Roush (2005) questionou a mudança de comportamento e cultura trazidos pela Web 2.0 ao apontar os smartphones como objetos digitais que aproximam pessoas de suas redes, considerando este como o maior promotor de conexões da sociedade moderna o que sugeria que a rede transformava a sociedade. A inspiração de Roush se deu em uma praça onde ele percebeu que grande parte das pessoas estavam "sozinhas" em um "estado de contemplação aos seus smartphones", chegando a conclusão de que a maioria da "computação" realizada no mundo agora estava voltada a conectar pessoas já que a Internet já estava disponível como, quando e onde o usuário desejar.

A Pricewaterhouse Coopers (2012) apresentou aquilo em que havia se transformado a Web 2.0 ao definir o modelo SMAC (Social, Mobile, Analytic \& Cloud). Para estes a Internet havia se tornado um ambiente de personalização onde o usuário poderia carregar a sua Internet (Móvel), em qualquer dispositivo (Nuvem), ter acesso as suas principais redes (Social) com o auxílio de sistemas de análise de dados para tornar o serviço mais agradável (Analítico).

A Internet deixava de ser um espaço estático, modelado de forma determinística pelo usuário, para ser um espaço inteligente que se ajustava de forma mais adequada para cada indivíduo e essa guinada no sentido da personalização foi percebida por algumas pessoas/empresas (MEIRA, 2015).

É nesse momento que se visualiza a necessidade, em grande escala, dos AIIs interagindo com seres humanos para compreender comportamentos na rede com o intuito de aprimorar a personalização da rede. No contexto SMAC, isso significa capturar todas as atividades do 
indivíduo na rede, entender os seus hábitos virtuais e conceber serviços orientados ao perfil daquele consumidor. O que tornou possível a existência dos AIIs na rede não foi a evolução da web para 2.0 e sim graças a web-semântica que tornou a rede compreendida por tais agentes e que culminou no surgimento da Web 3.0.

\section{A web 3.0 e as máquinas sociais}

Bernes Lee (1999) idealizou que a web seria populada por pessoas e AIIs em constante colaboração onde as pessoas fariam toda a parte criativa do trabalho enquanto que os agentes fariam toda a parte de administração deste espaço. Sabemos que hoje tais agentes trabalham com a finalidade de processar informações criadas pelos seres humanos para que estes usuários acessem conteúdo/serviços da rede mais interessantes para si mesmos. Com a atual complexidade da própria rede, para que um AII realize a tarefa de conhecer usuários, pode ser que este tenha que interagir com outras pessoas ou, até mesmo, outros AIIs detentores de informações daquele indivíduo.

Semmelhack (2013) afirma que entidades de softwares que possuem essa habilidade de se conectar tanto à pessoas quanto a outras máquinas são chamados de máquinas sociais. Uma máquina social é um ente que compreende tanto seres humanos quanto tecnologia e que ao interagir com estes produzem resultados que não seriam possíveis sem ambas as partes presentes no processo. Burégio, Meira e Rosa (2013) definem as máquinas sociais como aquelas capazes de: (i) construir estruturas sociais (software social), (ii) de se socializar de forma autônoma e inteligente com outros softwares ou seres humanos (software como entidades sociáveis) e (iii) que pode ter o auxílio de seres humanos para realizar suas atividades (pessoas como unidades computacionais). Ou seja, softwares capazes de identificar e participar de diversos fluxos de informações de forma autônoma e independente. Os autores sugerem uma estrutura para as máquinas sociais e a disposição de alguns elementos associados a eles como pode ser visto na Figura 2. 
Figura 2 - Máquinas Sociais

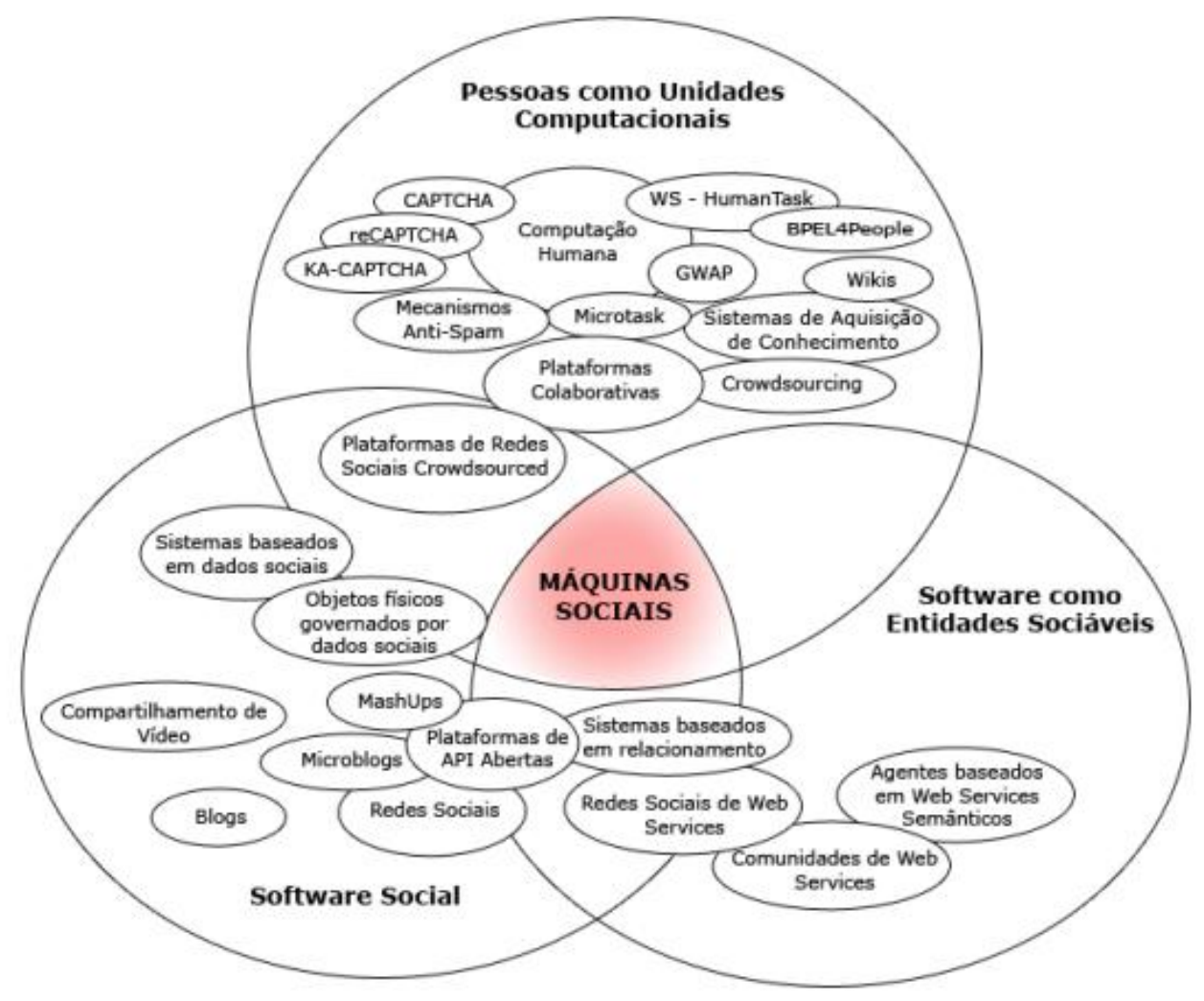

Fonte: Adaptado de Burégio, Meira e Rosa (2013)

Os estudos sobre os AIIs ainda são escassos, Tsvetkova et al (2016) afirmam que pouco se conhece a respeito do comportamento dos bots existentes na Internet. Considerando especificamente a CI, a teoria das máquinas sociais pode ser usada para construir uma visão própria sobre os impactos sociais da comunicação máquina-máquina e do papel dos AIIs nos processos de informação existentes na Internet.

Apenas para exemplificar o quão AIIs já fazem partes de ciclos de informação na Internet, podemos tomar o ciclo de vida da informação, mostrado na Figura 3, elaborado pelo Programa de Pós-Graduação em Ciência da Informação (PPGCINF) da Universidade Federal de Brasília (UNB), que apresenta uma extensa quantidade atividades relativas à informação. Das 29 etapas propostas neste ciclo, apenas as etapas de Projeto, Criação e Planejamento não podem ser executadas, de forma autônoma, por AIIs o que reafirma a possibilidade de estudos no tema pela CI. 
Figura 3 - Ciclo da informação do PPGCINF

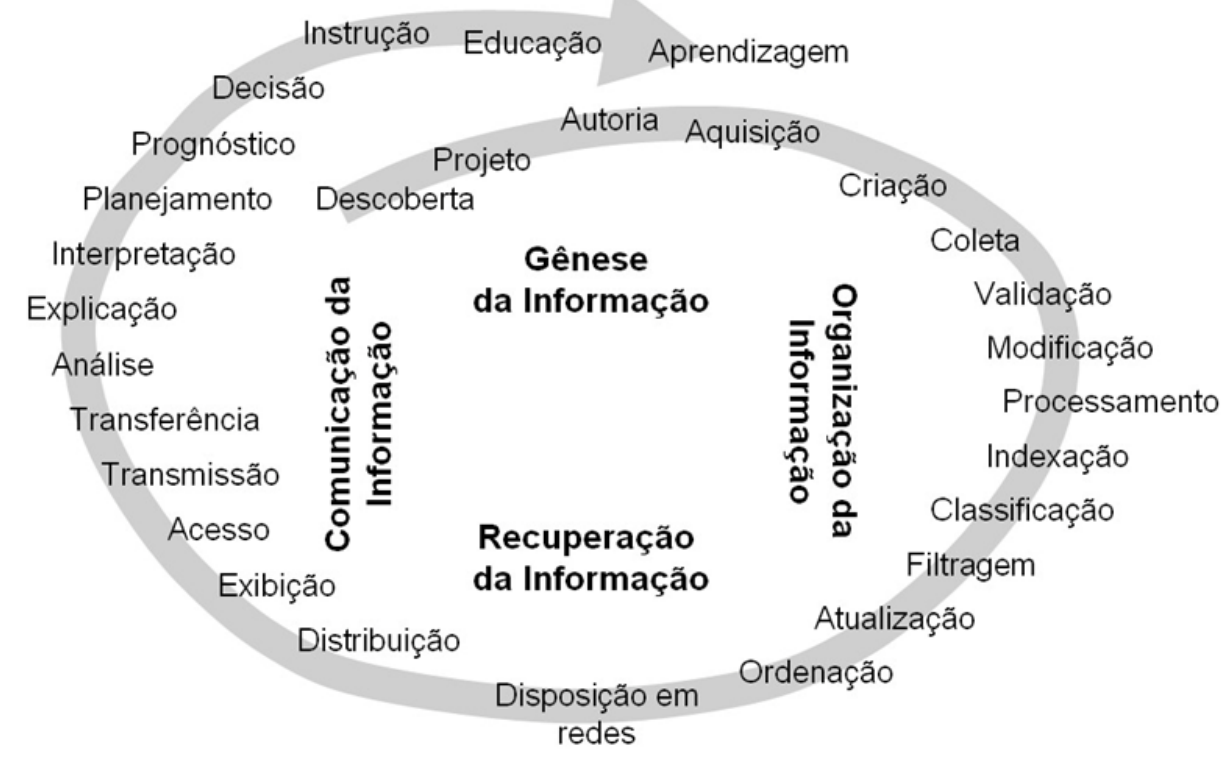

Fonte: Programa de Pós-Graduação em Ciência da Informação de Brasília.

Disponível em: http://ppgcinf.blogspot.com.br/p/informacoes-sobreorganizacao.html

\section{Considerações finais}

Os fenômenos relativos à informação se tornam cada vez mais presentes no dia-a-dia das pessoas chamando a atenção de pesquisadores de diversas áreas de conhecimento que passam a analisar um dos aspectos mais notáveis da condição humana que é a relação entre o ser humano e a informação. Se o paradigma pós-custodial veio reforçar o papel das pessoas e destacar a importância destas nos processos relativos a informação, existe hoje um apelo de outra parcela da comunidade acadêmica que questiona por que não ol har para os AIIs como entes ativos nos regimes de informação e não mais apenas como ferramentas para mediação de comunicação entre as pessoas.

A contribuição desta pesquisa para a academia é percebida de duas formas: a primeira é apresentar pontos convergentes da Ciência da Informação com outras áreas de conhecimentos que contribuíram para a criação dos AIIs. É notório que todo o desenvolvimento técnico que resultou na concepção dos AIIs surgiu com o intuito de solucionar questões relativas à informação. Assim, é cabida uma visão social sobre as ações dos AIIs e como estes influenciam a sociedade. A segunda forma 
é a sugestão do uso do arcabouço de conhecimento das máquinas sociais em pesquisas relativas aos AIIs na CI.

Desta forma podemos vislumbrar como trabalhos futuros a utilização do arcabouço de conhecimento das máquinas sociais para investigar fenômenos relativos à informação tais como disseminação da informação, ética, recuperação da informação, fluxos informacionais, estudos do usuário (bots), regimes de informação, ecologia da informação e a relação da sociedade com a informação tratadas por estes AIIs. Todos os temas citados já são objetos de estudo da CI considerando apenas os seres humanos no processo. As propostas para trabalhos futuros aqui apresentadas não sugerem que os AIIs sejam os sujeitos alvos da pesquisa, mas sim como o cotidiano das pessoas é influenciado pelas informações acessadas e processadas por estes agentes.

Por fim, destaca-se que a CI já possui uma discussão madura no que concerne a Web 2.0 e como as redes sociais influenciam a relação usuário/informação. Entretanto, estudos voltados para Web 3.0 e Web 4.0 (Internet Ubíqua) ainda estão à margem dos principais veículos de comunicação sugerindo um amplo campo de investigação não só para investigação dos AIIs, mas de outros assuntos relacionados a informação nesses novos contextos da Internet.

\section{Referências}

AABOE, A. Episodes from the early history of mathematics. MAA, v.13, 1964.

AHARONY, N.; REED, D. ; LIPPMAN, A. Social area networks: Data networking of the people, by the people, for the people. In: COMPUTATIONAL SCIENCE AND ENGINEERING, 2009. Anais [...]. Nova York, IEEE, 2009.

ANJOS, L. Sistemas de Classificação do Conhecimento na Filosofia e na Biblioteconomia: Uma visão histórico-conceitual crítica com enfoque nos conceitos de classe, de categoria e de faceta. Dissertação (Mestrado em Ciência da Informação) - Universidade de São Paulo, São Paulo. 2008.

BERNERS-LEE, T. Weaving the Web: The Past, Present and Future of the World Wide Web by Its Inventor. London: Orion Business Books, 1999.

BERNERS-LEE, T. The Semantic Web. Scientific American, May 2001. Disponível em: https://www.scientificamerican.com/article/the-semanticweb/. Acesso em: 22 mar. 2021.

BIOLCHINI, J. Semântica na representação do conhecimento: do vocabulário controlado à ontologia. In: ENCONTRO NACIONAL DE 
PESQUISA EM CIÊNCIA DA INFORMAÇÃO, V, 2003. Anais [...]. Rio de Janeiro: IBICT, 2003.

BUSH, V. As We May Think. The atlantic monthly, v. 176, n. 1, 1945. p. 101-10.

BURÉGIO, V., MEIRA, S., ROSA, N. Social machines: a unified paradigm to describe social web-oriented systems. In: INTERNATIONAL CONFERENCE ON WORLD WIDE WEB COMPANION, 22, 2013. New York. Anais [...]. New York, p. 885-890, 2013

CASTELLS, M. A sociedade em rede. São Paulo: Paz e Terra, 1999.

CASTELLS, M. A Galáxia Internet: reflexões sobre a Internet, negócios e a sociedade. Zahar, 2003.

CRNKOVIC, G. Shifting the Paradigm of the Philosophy of Science: the Philosophy of Information and a New Renaissance. Minds and Machines, v.13, n.4. 2003. Disponível em:

https://link.springer.com/article/10.1023/A:1026248701090. Acesso em: 22 mar. 2021.

DAHLBERG, I. Teoria da classificação, ontem e hoje. In: CONFERENCIA BRASILEIRA DE CLASSIFICAÇÃO BIBLIOGRÁFICA, 1976, Rio de Janeiro. Anais [...]. Rio de Janeiro: IBICT, 1979.

DUQUE, C., CARVALHÊDO, S. web semântica, as redes so ciais e o futuro dos profissionais da informação. In: ENCONTRO NACIONAL DE PESQUISA EM CIÊNCIA DA INFORMAÇÃO, v. 9, 2008. Anais [...]. ANCIB, 2009.

FLORIDI, L. Internet: which future for organized knowledge, Frankenstein or Pygmalion. International journal of human-computer studies, v.43, p.261-274, 1995. Disponível em:

https://uhra.herts.ac.uk/bitstream/handle/2299/1823/901824.pdf?sequen $\underline{\mathrm{ce}=1}$. Acesso em: 22 mar. 2021 .

FLORIDI, L. Information ethics: an environmental approach to the digital divide. Philosophy in the Contemporary World, v. 9, n. 1, p. 39-45, 2002.

FLORIDI, L. The fourth revolution: how the infosphere is reshaping human reality. Oxford: Oxford University Press, 2014.

GARCIA, J., SOUSA, M. Cultura digital: odisseia da tecnologia e da ciência. Em Questão, v. 17, n. 2, 2013. Disponível em: https://seer.ufrgs.br/EmQuestao/article/view/22252/14320. Acesso em: 22 mar. 2021. 
GEHRINGER, M., LONDON, J. Odisseia digital. 2001. Disponível em: http://www.geocities.ws/teeboheli/anexos/odisseiaDigital2.pdf. Acesso em: 2 jun. 2016.

GLEICK, J. A informação: Uma história, uma teoria, uma enxurrada. São Paulo: Companhia das Letras, 2013.

GUEDES, W., ARAÚJO JÚNIOR, R. Estudo das similaridades entre a teoria matemática da comunicação e o ciclo documentário. Informação \& Sociedade, v. 24, n. 2, 2014. Disponível em: https://periodicos.ufpb.br/ojs/index.php/ies/artide/view/16498. Acesso em: 22 mar. 2021.

HEIMS, J. John von Neumann and Norbert Wiener. Cambridge: MIT Press, 1980.

HERKEN, R. The Universal Turing Machine. A Half-Century Survey. Oxford: Oxford University Press, 1992.

JORENTE, M.; SANTOS, P.; VIDOTTI, S. Quando as Webs se encontram social e semântica: promessa de uma visão realizada? Informação \& Informação, v. 14, n.1esp., p. 1-24, 2009. Disponível em: http://www.uel.br/revistas/uel/index.php/informacao/article/view/2215/3 209. Acesso em: 22 mar. 2021.

KOPETZ, H. Internet of things. In: KOPETZ, H. Real-time systems. Springer US, 2011.

KURZWEIL, R., RICHTER, R., SCHNEIDER, M. The age of intelligent machines. Cambridge: MIT Press, 1990.

LÉVY, P. A inteligência coletiva. São Paulo: Loyola, 1998.

LÉVY, P. Cibercultura. São Paulo: Editora 34, 2010.

MANESS, J. Teoria da Biblioteca 2.0: Web 2.0 e suas implicações para as bibliotecas. Informação \& Sociedade, v. 17, n. 1, 2007. Disponível em: https://brapci.inf.br/ repositorio/2010/11/pdf d1b75c96ad 0012775.pdf. Acesso em: 22 mar. 2021.

MATHEUS, R. Rafael Capurro e a filosofia da informação: abordagens, conceitos e metodologias de pesquisa para a Ciência da Informação. Perspectivas em Ciência da Informação, v. 10, n. 2, 2005. Disponível em: http://portaldeperiodicos.eci.ufmg.br/index.php/pci/article/view/341. Acesso em: 22 mar. 2021. 
MEIRA, S. Novos negócios inovadores de crescimento empreendedor no Brasil. São Paulo: Leya, 2015.

MUHERONI, M. O paradigma físico da informação, segundo James Gleick. In: SILVA, J; PALETTA, F. (Orgs.) Tópicos para ensino de biblioteconomia. São Paulo: ECA-CBD, 2016. P. 166-175. v. 1.

NEIL, S. The Late George Boole. 1865. Tese (Doutorado em Matématica) Queen's College, Cork.

OTLET, P. Traité de Documentation: Le livre sur le Livre - Théorie et pratique. Bruxelles: Mundaneum, 1934.

PECKHAUS, V. Calculus ratiocinator versus characteristica universalis? The two traditions in logic, revisited. History and Philosophy of Logic, v. 25, n. 1 , p. 3-14, 2004.

PIERUCCINI, I. Fundamentos em Biblioteconomia, Documentação e Ciência da Informação. 2013. Disponível em:

https://www.passeidireto.com/arquivo/6393254/pieruccini-ivetefundamentos-em- biblioteconomia-documentacao-e-ci/2. Acesso em: 01 fev. 2016.

POMBO, O. Dispersão e unidade para uma poética da simpatia. In: LARA, M.; SMIT, J. (Orgs). Temas de Pesquisa em Ciência da Informação no Brasil. São Paulo: USP, 2010.

PRICEWATERHOUSE, $\mathrm{H}$. The business value of APIs. 2012 Disponível em: http://www.pwc.com/us/en/technologyforecast/2012/issue2/download.html. Acesso em: 23 abr. de 2016.

RECUERO, R. Redes sociais na internet. Porto Alegre: Sulina, 2011.

ROSENBLUETH, A., WIENER, N., BIGELOW, J. Behavior, purpose and teleology. Philosophy of science, v. 10, n. 1, 1943. Disponivel em: https://www.jstor.org/stable/184878?refreqid=excelsior\%3A4862a6a1c17 dfdcda1f2ef5a0af6a1eb\&seq=1. Acesso em: 22 mar. 2021.

ROUSH, W. Social machines: Computing means connecting. Technology Review, v. 108, n. 8, p. 44, 2005.

SEMMELHACK, P. Social machines: how to develop connected products that change customers' lives. New York: John Wiley \& Sons, 2013.

SHANNON, C., WEAVER, W. The mathematical theory of information. 1949. 
SOLOVE, D. The digital person: Technology and privacy in the information age. New York: Ny U. Press, 2004.

TOFFLER, A. A Terceira Onda. São Paulo: Record, 2007.

TSVETKOVA, M., GARCIA-GAVILANES, R., FLORIDI, L. Even Good Bots Fight. 2016. Disponível em: https://arxiv.org/abs/1609.04285. Acesso em: 23 abr. 2016.

TURING, A. Computing machinery and intelligence. Mind, v. 59, n. 236, 1950. Disponível em:

https://www.csee.umbc.edu/courses/471/papers/turing.pdf. Acesso em: 22 mar. 2021.

VICKERY, A; VICKERY, B. Information science in theory and practice. Berlim: Walter de Gruyter, 2004.

1 https://www.incapsula.com/blog/bot-traffic-report-2015.html

$\underline{2}$ www.wikipedia.com

$\underline{3}$ http://goo.gl/ONtVlj

4 Visicalc foi o primeiro programa de planilha eletrônica utilizado em computadores pessoais. Lançado em 1979 para computadores Apple II e foi o primeiro programa de computador a vender mais de 10 milhões de cópias. 